\title{
Growth and Characterization Studies: Potential Nonlinear Optical Single Crystals Hippuric Acid (HA)
}

\author{
A. Kumaresh, R. Arun Kumar* \\ GRD Centre for Materials Research, PSG College of Technology, Coimbatore, India \\ *Corresponding author: rarunpsgtech@yahoo.com
}

Copyright $@ 2014$ Horizon Research Publishing All rights reserved.

\begin{abstract}
Organic non-linear optical materials receive much attention owing to their very large second order nonlinearities, ultra-fast response times and high optical damage thresholds. In the present work, low temperature solution growth technique has been employed to grow non-linear optical hippuric acid (HA) $\mathrm{C}_{6} \mathrm{H}_{5} \mathrm{CONHCH}_{2} \mathrm{COOH}$ single crystal with dimensions $10 \mathrm{x}$ $6 \times 3 \mathrm{~mm}^{3}$ were obtained in a period of 18 days using acetone as solvent. Powder XRD analysis reveals that the crystal belongs to an orthorhombic system with space group P $2{ }_{1} 2{ }_{1} 2_{1}$ and lattice parameters were found to be $\mathrm{a}=8.8514 \AA, \mathrm{b}=$ $9.0842 \AA, \mathrm{c}=10.5807 \AA$. UV optical absorption analysis on these samples reveals the transparency of the crystal in the visible region. The bonding structure and molecular associations due to chemical reactions were analyzed by FTIR spectroscopy.
\end{abstract}

Keywords Growth from Solution, NLO Property, SHG, Powder XRD, UV-Vis-NIR, FTIR

\section{Introduction}

Coherent radiation from common lasers can be converted to any other desirable wavelengths using nonlinear optical (NLO) effects by means of NLO crystals. Electronic and photonic materials are the key elements for the scientific growth and technological advances in new millennium. The nonlinear optical (NLO) organic materials have been the subject of extensive theoretical and experimental investigations during the past two decades [1-2].

Nonlinear optics (NLO) has wide applications in the field of telecommunication and information devices [3-6]. Nonlinear optics is playing a major role in the emerging photonics and optoelectronics technologies. New non linear optical frequency conversion materials have a significant impact on laser technology, optical communication and optical data storage [7-9]. Organic NLO materials are attracting a great deal of attention for possible use in optical devices because of their large optical non linearity, low cutoff wavelength, short response time and high threshold for laser power [10-12].

Recent interest in quantum electronics has centered on finding a new materials for efficient second harmonic electro optic modulation [13]. The organic NLO material contains an optically active atom i.e. it will have hyper polar molecule, which favors the formation of big size crystals [14]. Hippuric acid (HA) with molecular formula $\mathrm{C}_{6} \mathrm{H}_{5}$ $\mathrm{CO}-\mathrm{NH}-\mathrm{CH}_{2}-\mathrm{COOH}$ is also referred as benzamino acetic acid is an organic nonlinear material. It is formed in the order of orthorhombic structure. It is an excellent crystal for second harmonic generation because of its high conversion efficiency [15]. In the present work, investigation with various solvents have been taken for the growths of hippuric acid single crystal and found that, defect-free crystals of HA can be grown using acetone as a solvent.

\section{Single Crystal Growth}

Low temperature solution growth technique has been employed to grow HA single crystal using acetone as solvent. The analytical grade HA was taken and dissolved in acetone to prepare the saturated solution. The saturated solution of HA was obtained by dissolving the material with continuous stirring of solution using magnetic stirrer. The resulting solution was filtered using borosil filter paper of porosity 0.1 $\mu \mathrm{m}$. The filtered solution was allowed to evaporate in a petri dish at ambient temperature. High quality transparent colourless crystals of size $10 \times 6 \times 3 \mathrm{~mm}^{3}$ were obtained in a period of 18 days. Its structural formula and molecular structure are shown in Fig $1 \& 2$ respectively. Its crystal structure projected along the a-axis is shown in Fig 3 and the photograph of grown HA crystal is as shown in Fig 4.

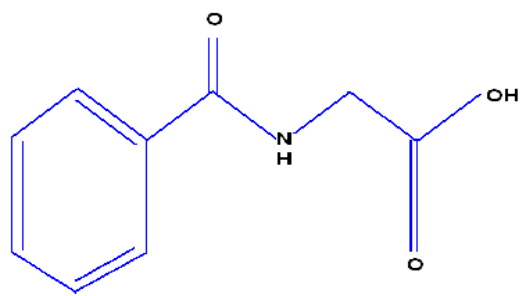

Figure 1. Structural formula of HA 


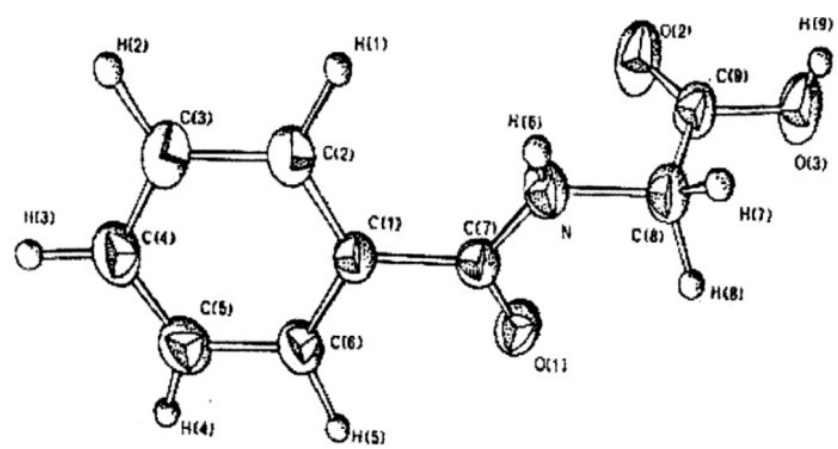

Figure 2. Molecular structure of HA

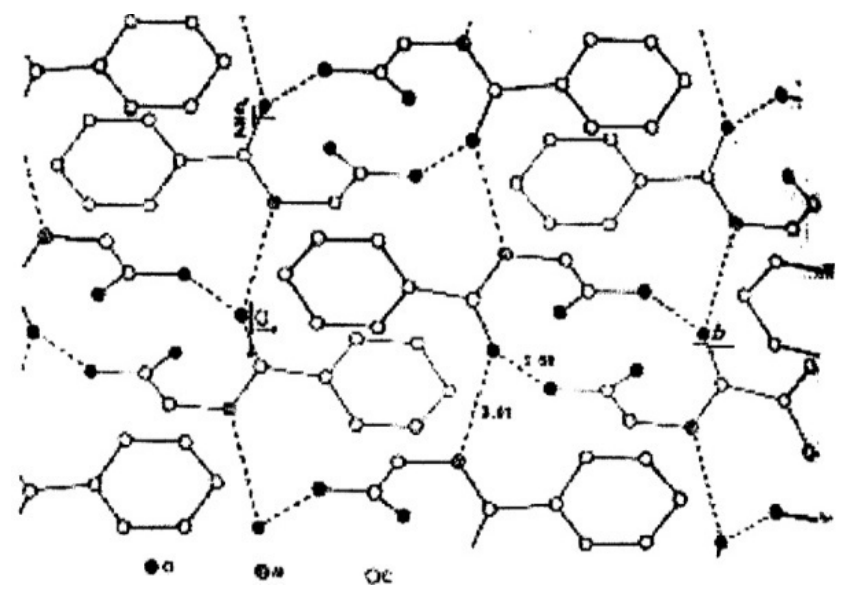

Figure 3. Crystal structure of HA projected along the a-axis

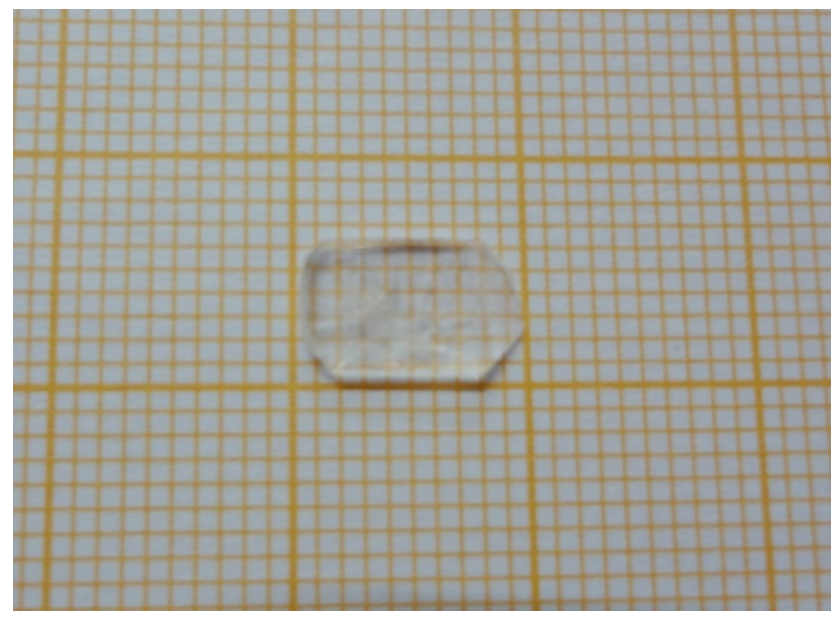

Figure 4. Photograph of HAADP single crystal

\section{Crystal Characterizations}

\subsection{Powder XRD Analysis}

The grown crystals of HA was powdered and subjected to X-ray diffraction analysis using STOE powder diffraction system loaded in Si-911 loader. The wavelength of X-ray radiation is $1.5406 \AA$. The anode voltage was $35 \mathrm{kV}$ with a current of $30 \mathrm{~mA}$. The range of $2 \theta$ was scanned from $10^{\circ}-$ $70^{\circ}$. Intensity versus $2 \theta$ was recorded for HA and shown in
Fig 5. From the powder X-ray diffraction data, the lattice parameters and the cell volume have been calculated using XRDA software package. It has been found that the crystal belongs to the orthorhombic system with space group $\mathrm{P} 2{ }_{1} 22_{1}$ and lattice parameters $\mathrm{a}=8.8514 \AA, \mathrm{b}=9.0842 \AA$, c $=10.5807 \AA$. The crystallography data is given in table 1 .

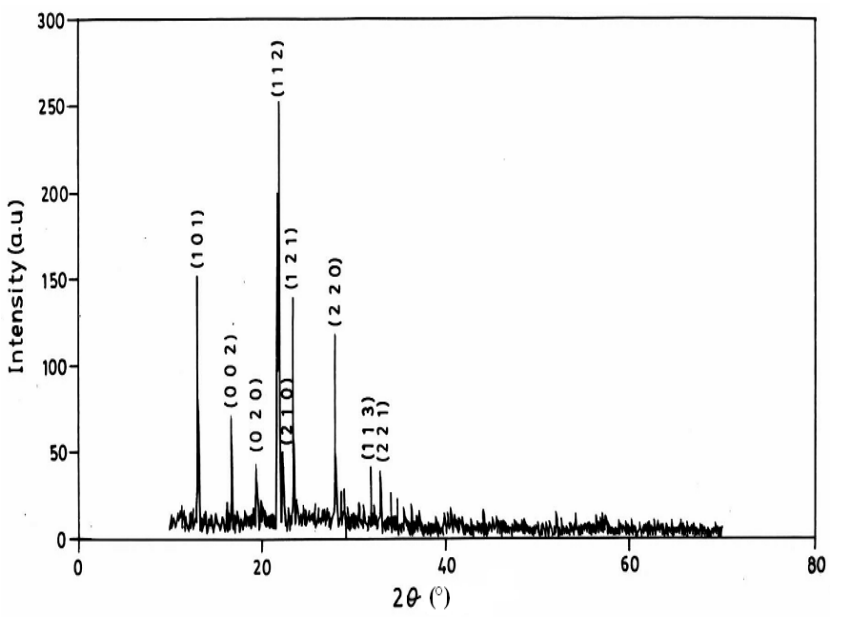

Figure 5. Powder XRD spectrum of HA crystal

\subsection{UV-Vis-NIR Analysis}

The grown crystal of HA was subjected to UV-Vis-NIR spectral analysis. A crystal of thickness $3 \mathrm{~mm}$ was used to record the spectrum in the wavelength range between 200 $1000 \mathrm{~nm}$ using Varian Cary 5E UV-Vis-NIR spectrometer. The UV absorption spectrum of HA is shown in Fig 7. It reveals that the HA crystal has wider transparency range extending into entire visible and IR region. It is evident that crystal has absorption around $300 \mathrm{~nm}$, which is may be assigned to electronic transition in the aromatic ring $\mathrm{C}=\mathrm{O}$ groups [5]. The cutoff wavelength around $300 \mathrm{~nm}$ is sufficiently good for second harmonic generation and other applications in the blue region [10].

\subsection{FTIR Analysis}

FTIR spectrum was taken from the synthesized sample by pelletizing them with spectroscopic $\mathrm{KBr}$ from Merck by applying a pressure of $370 \mathrm{MPa}$. The pressure was given through hydraulic press. The FTIR spectrum of HA is recorded in the range from 400 to $4000 \mathrm{~cm}^{-1}$ using $\mathrm{KBr}$ pellet technique by Brukker IFS 66v FTIR spectrometer. The spectrum obtained is shown in Fig 6. The characteristic absorption of HA and bond assignment of functional groups present in the grown crystal are given in the table 2 .

\section{Conclusions}

Optically good quality of nonlinear optical hippuric acid single crystals was grown by solution growth technique. The X-ray diffraction study revealed that the grown crystal 
belongs to orthorhombic system. FTIR analysis confirms the functional groups present in the crystal. The optical absorption analysis revealed that Hippuric acid crystals have a UV cutoff wavelength around $300 \mathrm{~nm}$ and has wider transparency range extending into entire visible and IR region. From this optical assessment we found that it has large transmission range and it may be used for frequency doubling and other optical application.

Table 1. Unit cell parameters of HA crystal

\begin{tabular}{|c|c|c|c|c|c|c|}
\hline \multirow{2}{*}{ Sample } & \multicolumn{3}{|c|}{ Lattice parameters } & \multirow{\alpha}{\alpha}{$=\beta=\gamma$} & Structure & Space group \\
\cline { 2 - 5 } & $\mathrm{a}(\AA)$ & $\mathrm{b}(\AA)$ & $\mathrm{c}(\AA)$ & $\left(^{\circ}\right)$ & & \\
\hline HA & 8.8514 & 9.0842 & 10.5807 & 90 & Orthorhombic & $\mathrm{P} 22_{1} 2_{1}$ \\
\hline
\end{tabular}

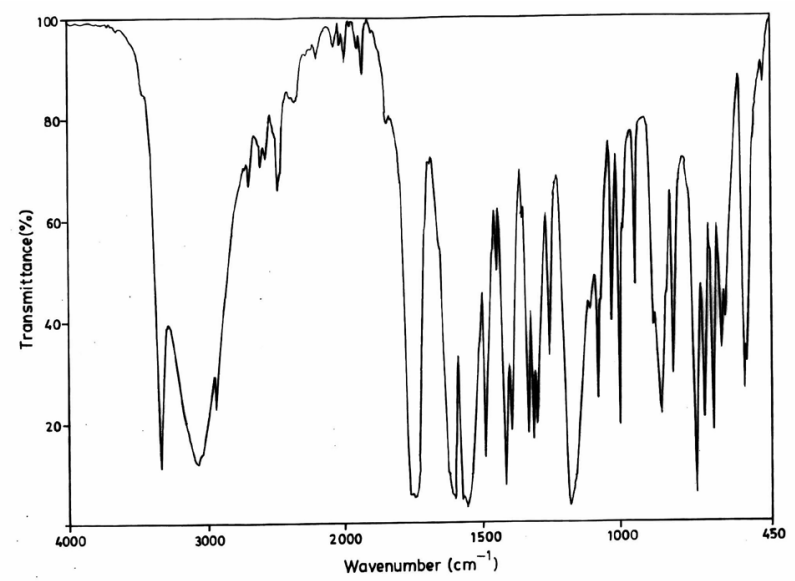

Figure 6. UV visible spectrum of HA

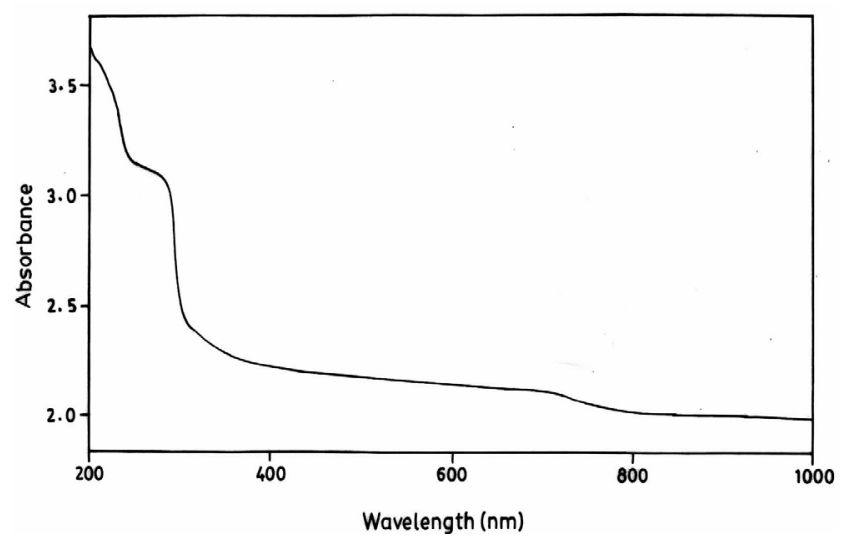

Figure 7. FTIR spectrum of HA crystal

Table 2. Characteristic absorption and bond assignment

\begin{tabular}{|c|c|}
\hline Characteristic absorption of HA $(\mathrm{cm}-1)$ & Bond assignments \\
\hline $3341 \mathrm{~cm}-1$ & $\mathrm{~N}-\mathrm{H}$ deformation \\
$3073 \mathrm{~cm}-1$ & Hydrogen bonded OH stretching \\
$2938 \mathrm{~cm}-1$ & $\mathrm{CH}$ stretching of $\mathrm{CH} 2$ \\
$1988 \mathrm{~cm}-1$ & $\mathrm{~N}-\mathrm{H}$ stretching \\
$1744 \mathrm{~cm}-1$ & $\mathrm{C}=\mathrm{O}$ stretching \\
$1600 \mathrm{~cm}-1$ & $\mathrm{C}=\mathrm{O}$ stretching of COOH group \\
$1465 \mathrm{~cm}-1$ & $\mathrm{C}-\mathrm{C}$ stretching \\
$1335 \mathrm{~cm}-1$ & $\mathrm{C}-\mathrm{N}$ stretching \\
$629 \mathrm{~cm}-1$ & $\mathrm{C}-\mathrm{H}$ deformation \\
\hline
\end{tabular}




\section{REFERENCES}

[1] M.D. Shirsat, S.S. Hussaini, N.R. Dhumane, V.G. Dongre, Cryst. Res. Technol. 43 (2008), $756-761$.

[2] R. Mohan Kumar, D. Rajan Babu, D. Jayaraman, R. Jayaval, K. Kitmura, J. Cryst. Growth. 275 (2005), 1935 - 1939.

[3] K. Meera, R. Muralidharan, R. Dhanasekaran, Manyum Prapun, P. Ramasamy, J. Cryst. Growth. 263 (2004), 510 516.

[4] R.N. Rai, P.Ramasamy, C.W.Lan, J. Cryst. Growth 235 (2002) 499.

[5] N.Vijayan, R. Ramesh Babu, M.Gunasekaran, R.Gopalakrishnan, R. Kumaresan, P.Ramasamy, C.W.Lan, J.Cryst. Growth 249 (2003) 309.

[6] S.Selvakumar, S.M. Ravikumar, K.Rajarajan, A.Joseph, Arul Pragasa, S.A. Rajasekaran, K. Thamizharasan, P. Sagayaraj, J. Cryst. Growth 11 (2006) 2607.

[7] Pricilla Jeyakumari, J. Ramajothi, S. Dhanuskodi, J. Cryst.
Growth.269 (2004), 558 -564.

[8] A.S. Haja Hameed, C.W. Lan, J. Cryst. Growth. 270 (2004), $475-480$.

[9] S.Ariponnammal, S.Radhika, R.Selva, N.Victor Jeya, Cryst. Res. Technol 40 (2005) 786.

[10] M. Narayan Bhat, S.M. Dharmaprakash, J. Cryst. Growth 243 (2002) 526-530

[11] P.Anand, G. Mohmad, S.A. Rajasekar, S.Selvakumar, A.Joseph, A.Pragasan, P.Sagayaraj, Mater. Chem. Phys. 97 (2006) 501.

[12] Wen-linwang, Mengwang, Wei-dong Huang, Opt. Mater. 27 (2004) 609.

[13] A.S. Haja Hameed, G.Ravi, R. Dhanasekaran, P. Ramasamy, J. Cryst. Growth 212 (2000) 227-232.

[14] C.K. Lakshmana Perumal, A. Archakkarvarthi, P. Santharagavan, J. Cryst. Growth. 241 (2002) 200-205.

[15] D.S. Chemla, J. Zyss (Eds), Nonlinear Optical Properties of Organic Molecules and Crystals, vol. 1, Orlando, Academic Press, 1987, pp.23-187. 